\title{
CrystEngComm
}

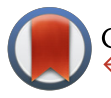

CrossMark flick for updates

Cite this: CrystEngComm, 2016, 18, 7629

Received 1st June 2016

Accepted 15th August 2016

DOI: 10.1039/c6ce01272h

www.rsc.org/crystengcomm

\section{A stimuli-responsive $A u(I)$ complex based on an aminomethylphosphine template: synthesis, crystalline phases and luminescence properties $\uparrow$}

\author{
Igor D. Strelnik, ${ }^{\text {ab }}$ Vladislav V. Gurzhiy, ${ }^{c}$ Vladimir V. Sizov, ${ }^{b}$ Elvira I. Musina, ${ }^{a}$ \\ Andrey A. Karasik, ${ }^{a}$ Sergey P. Tunik ${ }^{\star b}$ and Elena V. Grachova*b
}

\begin{abstract}
Herein we report the synthesis of a stimuli-responsive binuclear $A u(1)$ complex based on the 1,5-bis(ptolyl)-3,7-bis(pyridine-2-yl)-1,5-diaza-3,7-diphosphacyclooctane ligand, which is a novel template for the design of luminescent metal complexes. In the solid state, the complex obtained gives three different crystalline phases, which were characterized by XRD analysis. It was also found that the crystalline phases can be reversibly interconverted by recrystallization or solvent vapour treatment. The emission of these phases varies in the 500-535 nm range. Quite unexpectedly, the emission energy of these phases is mostly determined by the non-covalent interactions of the solvent molecules with the ligand environment, which have nearly no effect on the Au-Au interactions in the chromophoric centre. The complex obtained demonstrates thermo/solvatochromism to display greenish emission in a DCM matrix and blue emission in an acetone matrix at $77 \mathrm{~K}$, in contrast to the blue emission of the phase containing a DCM molecule and greenish-yellow emission of the acetone solvate in a crystal cell at room temperature. The potentially important role of co-crystallized solvent molecules in the ligand-based emission of the complex obtained is supported by DFT calculations.
\end{abstract}

\section{Introduction}

Luminescence of stimuli-responsive materials can be used in a wide range of smart technologies including applications in sensing trace amounts of organic vapours. ${ }^{1}$ It is well known that luminescence of solid state samples and, in particular, crystalline materials depends strongly on the local environment of chromophores ${ }^{2}$ and crystallinity ${ }^{3,4}$ of the corresponding phases. The $\mathrm{Au}(\mathrm{I})$ complexes are among the most promising candidates for the design of this type of materials due to a large variety of supramolecular structures, which display sensitivity to temperature, ${ }^{5}$ organic vapours, ${ }^{3,4,6}$ ions $^{7}$ and mechanical stress ${ }^{8}$ to give a response in luminescence intensity or in the wavelength of emission. These reactions onto exter-

\footnotetext{
${ }^{a}$ A. E. Arbuzov Institute of Organic and Physical Chemistry, Kazan Scientific Center of Russian Academy of Sciences, Arbuzov str. 8, 420088 Kazan, Russia ${ }^{b}$ Institute of Chemistry, St. Petersburg State University, Universitetskii pr. 26, 198504 St. Petersburg, Russia. E-mail: bird231102@mail.ru

${ }^{c}$ Institute of Earth Sciences, St. Petersburg State University, Universitetskaya nab. 7/9, 199034 St. Petersburg, Russia

$\dagger$ Electronic supplementary information (ESI) available: Synthetic procedure for 1 preparation; details of the transformation of the crystalline phases; details of the photophysical experiment; computational details; crystal data and structure refinement for 1a-c; bond lengths, angles and torsion angles for 1a-c. CCDC 1030853,1027244 and 1027245. For ESI and crystallographic data in CIF or other electronic format see DOI: 10.1039/c6ce01272h
}

nal stimuli are provoked by variations in the structure of materials mainly related to noncovalent interactions in the solid phase, such as the formation/breaking of aurophilic interactions, hydrogen bonding, $\pi-\pi$ stacking, etc. ${ }^{9}$ which affect the chromophoric centre characteristics. Phosphine or polyphosphine ligands are excellent templates for construction of polynuclear $\mathrm{Au}(\mathrm{I})$ complexes due to the stability of the $\mathrm{P}-\mathrm{Au}$ bond. Recently, we reported on the synthesis and characterization of mixed metal gold-copper alkynyl-phosphine complexes, the amorphous phase of which undergoes crystallization upon exposure to the vapours of polar organic solvents (methanol, THF, and acetone) to give a substantial blue shift and increase in the emission intensity. ${ }^{4}$ It is important to note that the effects cannot be completely explained by the direct interaction of the chromophore with the co-crystallized solvent but has been assigned to the cooperative effect of the phase crystallinity.

The cyclic aminomethylphosphines in common and 1,5diaza-3,7-diphoshpacyclooctanes in particular are convenient templates for the targeted design of $\mathrm{Au}(\mathrm{I})$ luminescent complexes due to easy functionalization of the framework at the heteroatoms of the cycle and their ability to vary framework conformation. ${ }^{10}$ Insertion of functional groups into the cyclic systems allows obtaining the ligands with desired properties (chirality, ${ }^{11}$ water-solubility, ${ }^{12}$ chromophoricity ${ }^{13}$ ) or enhanced reactivity. The conformation of the aminomethylphosphine 
cycle in the complexes depends on the metal oxidation state, solvent and temperature. ${ }^{14}$ For the copper subgroup metals, the 1,5-diaza-3,7-diphosphacyclooctanes preferably exist in "crown" conformation with nearly co-directed lone electron pairs at the phosphorus atoms. This conformation allows the disposition of the $\mathrm{Au}(\mathrm{I})$ ions in close proximity to each other, which in principle makes the formation of an aurophilic bond possible that in turn makes 1,5-diaza-3,7diphosphacyclooctanes prospective ligands for the design of stimuli-responsive $\mathrm{Au}(\mathrm{I})$ complexes.

In an attempt to search for stimuli responsive materials of this sort, herein we present a study of an $\mathrm{Au}(\mathrm{I})$ chloride complex based on pyridyl substituted 1,5-diaza-3,7diphosphacyclooctane. ${ }^{13}$ This is the first example of the application of 1,5-diaza-3,7-diphosphacyclootanes as a template for the design of luminescent complexes. The complex obtained shows a clear dependence of the luminescence properties on the nature of co-crystallized solvent (dichloromethane, acetone) and structure of the crystalline phases. It was also found that both crystallization from solution and solid phase recrystallization upon exposure to the solvent vapours cause identical effects that may be used in preparation of highly selective vapour sensing devices.

\section{Results and discussion}

\section{Synthesis and structural characterization of complex 1}

The ligand used in this study is a cyclic bisphosphine with a pyridyl function bound directly to the coordination centres of the ligand (P-atoms). 1,5-Bis( $p$-tolyl)-3,7-bis(pyridine-2-yl)-1,5diaza-3,7-diphosphacyclooctane (PNNP ligand) was synthesized according to the previously described method. ${ }^{13}$ The one-stage reaction shown in Scheme 1 gives the binuclear phosphine-chloride Au(I) complex (1) in high yield.

In solution, the compound obtained was characterized using ${ }^{31} \mathrm{P}$ and ${ }^{1} \mathrm{H}$ NMR spectroscopy and mass-spectrometry. The ${ }^{31} \mathrm{P}\left\{{ }^{1} \mathrm{H}\right\}$ NMR spectrum of 1 displays a singlet resonance at $9.9 \mathrm{ppm}$ generated by the equivalent phosphorus atoms of the PNNP ligand that is compatible with the idealized $\mathrm{C}_{2}$ symmetry group of the structural pattern shown in Scheme 1. The phosphorus signal is considerably down-field shifted compared to that of the free ligand $(-44.8 \mathrm{ppm})$ that clearly indicates ligand coordination to the $\mathrm{Au}(\mathrm{I})$ centre. The ${ }^{1} \mathrm{H}$ NMR spectrum of 1 (see Fig. S1†) also agrees well with this structural pattern. In the low field region (6.1-8.8 ppm) of the proton spectrum, a clearly resolved set of the signals corresponding to the aromatic protons of the pyridyl and $p$-tolyl
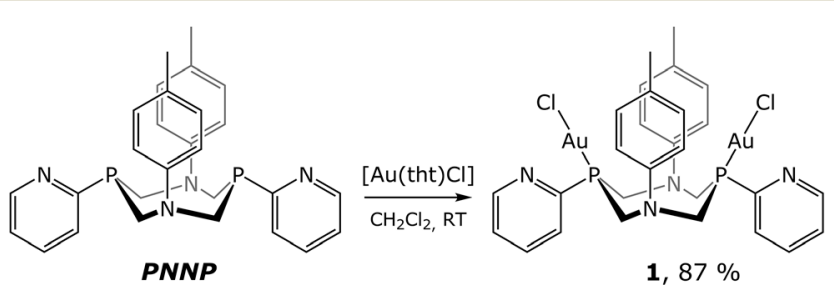

Scheme 1 Synthesis of the complex 1. groups of the diphosphine is displayed. The pyridyl function of this ligand remains uncoordinated in solution because the signal of the ortho-pyridyl proton, which is highly sensitive to $\mathrm{N}$-coordination, displays nearly the same chemical shift as that found for the free ligand (8.78 for 1 vs. 8.73 for PNNP). The $p$-tolyl protons in the spectrum of 1 give $\mathrm{AB}$ systems in the 6.95-7.0 ppm range. The protons of the $\mathrm{P}-\mathrm{CH}_{2}-\mathrm{N}$ fragments appear in the 4.5-5.0 ppm interval as two dd signals of an $\mathrm{ABX}$ system that is a clear indication of the diastereotopic positions of the hydrogen atoms. ${ }^{13}$ The ${ }^{2} J_{\mathrm{HH}}$ $15.6 \mathrm{~Hz}$ and ${ }^{2} J_{\mathrm{PH}} 2.0 \mathrm{~Hz}$ coupling constants of the axial methylene protons indicate the ligand "crown" conformation similar to that of the free aminomethylphosphine frameworks. The high field area of these spectra displays the singlet resonance of the methyl protons of the $p$-tolyl group at about $2.3 \mathrm{ppm}$.

Thus, the number of signals in the phosphorus and proton spectra, their multiplicity and relative intensity are completely compatible with the structural pattern shown in Scheme 1. The $\mathrm{ESI}^{+}$mass spectrum of 1 contains the signal corresponding to a monocation $\left[\mathrm{M}-\mathrm{Cl}^{-}\right]^{+}$. The $\mathrm{m} / z$ values and isotopic pattern of the signal agree exactly with the calculated spectrum of this ion (Fig. $\mathrm{S} 2 \dagger$ ).

\section{Solid state structure of complex 1}

The single crystal X-ray diffraction study of the solid phasest (for details see the Notes and References section, the ESI $\dagger$ and Table S1) obtained upon crystallization of 1 from various solvents revealed that crystallization from dichloromethane (1a), acetone (1b) and a mixed solvent system (dichloromethane/acetone $=20 / 1)(1 \mathrm{c})$ gives three different phases, which display very similar molecular structural patterns but vary considerably in packing of the crystal cell (see Fig. 1, S3†). It is also worth noting that interconversion between the a, b, c phases of $\mathbf{1}$ may occur not only through crystallization from the corresponding solvents but also by treatment of the solid phase samples with the solvent vapours as shown in Scheme 2.

The 1a-c crystals contain molecules of the solvent (dichloromethane - 1a, acetone - 1b and 1c), which occupy essentially different positions in the crystal cell and fill available voids in the crystal lattice. It has been also found that in

$\ddagger$ The crystal structures of $\mathbf{1 a}-\mathbf{c}$ were determined by means of single crystal X-ray diffraction analysis using Rigaku Oxford Diffraction Supernova Atlas (1a) and Excalibur Eos $(\mathbf{1 b}, \mathbf{1 c})$ diffractometers at a temperature of 100 K. 1a: $\left(\mathrm{C}_{28} \mathrm{H}_{30} \mathrm{Au}_{2} \mathrm{Cl}_{2} \mathrm{~N}_{4} \mathrm{P}_{2}\right) \cdot\left(\mathrm{CH}_{2} \mathrm{Cl}_{2}\right)_{3}, P 2 / c, a=15.3277(5), b=8.8720(2), c=14.8008(6)$ $\AA, \beta=112.309(4)^{\circ}, V=1862.06(12) \AA^{3}, Z=2, R_{1}=0.044$, CCDC 1030853. 1b: $\left(\mathrm{C}_{28} \mathrm{H}_{30} \mathrm{Au}_{2} \mathrm{Cl}_{2} \mathrm{~N}_{4} \mathrm{P}_{2}\right) \cdot\left(\mathrm{C}_{3} \mathrm{H}_{6} \mathrm{O}\right), P 2 / c, a=8.8698(2), b=10.6900(3), c=17.5273(5) \AA$, $\beta=96.988(3)^{\circ}, V=1649.56(8) \AA^{3}, Z=2, R_{1}=0.026$, CCDC 1027244. 1c: $\left(\mathrm{C}_{28} \mathrm{H}_{30} \mathrm{Au}_{2} \mathrm{Cl}_{2} \mathrm{~N}_{4} \mathrm{P}_{2}\right) \cdot\left(\mathrm{C}_{3} \mathrm{H}_{6} \mathrm{O}\right)_{2}, \quad C 2 / m, \quad a=24.029(4), \quad b=16.9105(16), c=$ 12.0433(18) ̊, $\beta=124.55(2)^{\circ}, V=4030.5(13) \AA^{3}, Z=4, R_{1}=0.035$, CCDC 1027245. The structures were solved by direct methods and refined using the SHELXL-97 program incorporated in the OLEX2 program package. Absorption correction was applied in the CrysAlisPro program complex. The unit cell of 1a $\cdot 3 \mathrm{CH}_{2} \mathrm{Cl}_{2}$ contains disordered dichloromethane molecules that have been treated as a diffuse contribution to the overall scattering without specific atom positions by SQUEEZE/PLATON. ${ }^{15}$ 


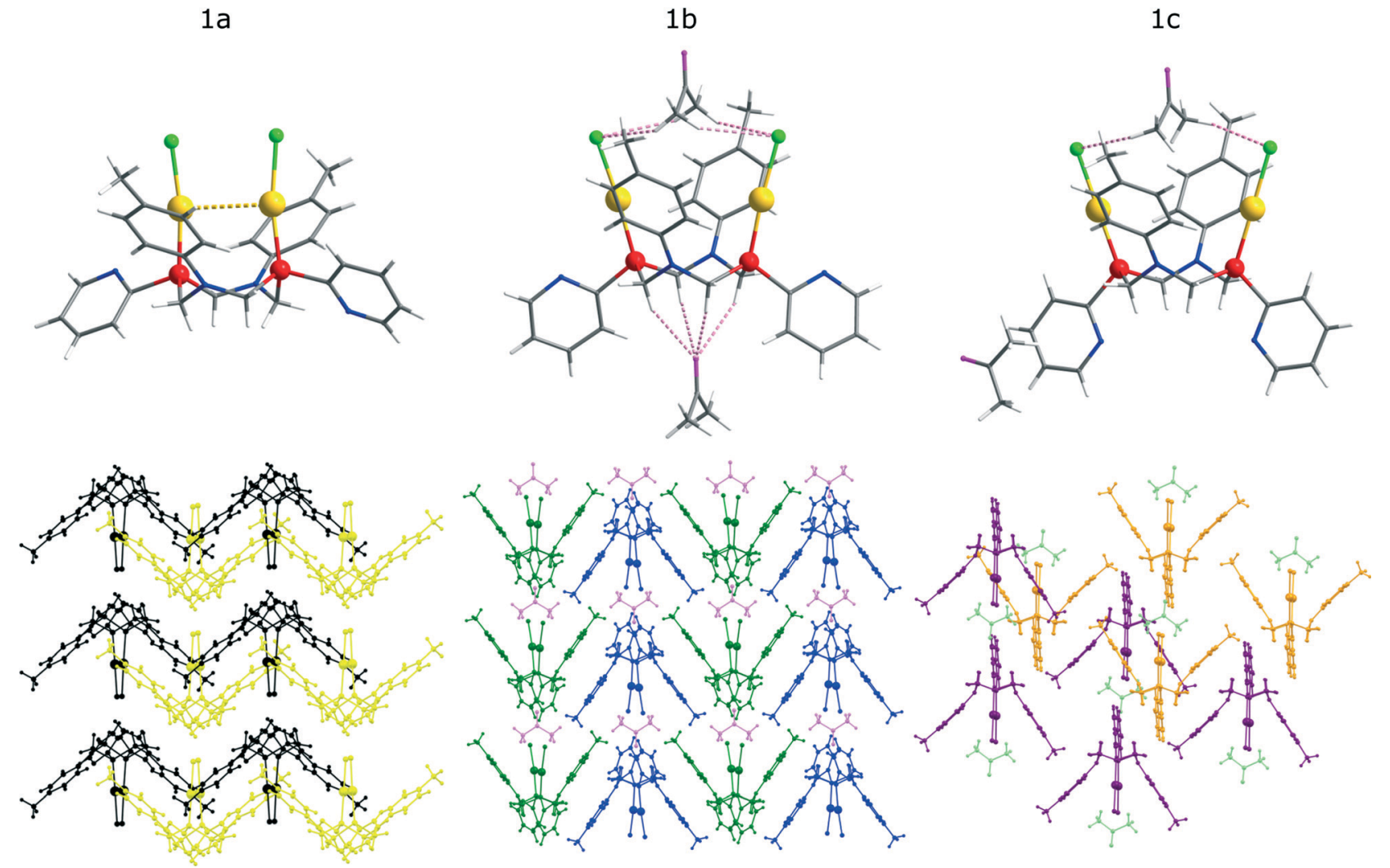

Fig. 1 Top: Molecular view of 1a-c (colour legend: gold, yellow; nitrogen, blue; phosphorous, red; oxygen, magenta; chlorine, green; carbon, grey; hydrogen, light grey). Bottom: Crystal packing of 1a-c showing "host-guest" aggregates with acetone molecules (the crystalline phase 1a contains no acetone).

the solid state a molecule of 1 demonstrates conformational isomerism related either to the formation of aurophilic bonding in 1a or to its ability to form "host-guest" aggregates with the solvent molecules in $\mathbf{1 b}$ and $\mathbf{1 c}$ (see Fig. 1.) The PNNP ligand in the complex molecule in 1a-c crystals has a "crown" conformation with the $\mathrm{C}_{2}$ symmetry of the structural pattern. This conformation and axial orientation of $p$-tolyl substituents at nearly planar nitrogen atoms give a "basket" shape cavity, which may be contracted because of aurophilic bonding (1a) or exist in open form (1b and 1c) that makes hosting of a solvent molecule possible. In the crystal cell of $1 \mathrm{a}$, the solvent (DCM) does not display short intermolecular contacts with the complex and occupies the positions outside the

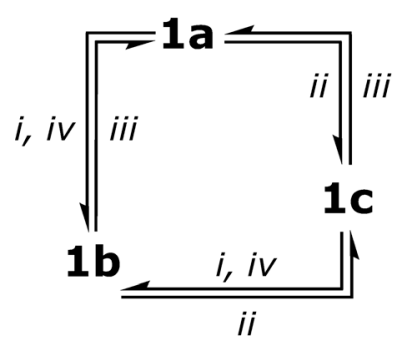

Scheme 2 Interconversion of the complex 1 crystalline phases upon crystallization or solvent vapour exposition: i crystallization from acetone; ii crystallization from the DCM/acetone mixture; iii crystallization from DCM; iv acetone vapour treatment. "basket" cavity that allows intramolecular aurophilic bonding (Au-Au distance of $3.313 \AA$ A; Table 1) due to the flexible backbone of the PNNP ligand.

In the $\mathbf{1 b}$ and $1 \mathrm{c}$ crystalline phases, the intramolecular $\mathrm{Au} \cdots \mathrm{Au}$ distances are substantially longer (5.388 and 5.956 ̊, respectively), which indicate the absence of aurophilic interactions in the open "basket" conformation. The open mode of the "basket" cavity in $\mathbf{1 b}$ and $\mathbf{1 c}$ is "ready-to-host" an acetone molecule and to form a "host-guest" system with rather strong hydrogen $(\mathrm{H}-\mathrm{O}, \mathrm{H}-\mathrm{Cl})$ bonding between acetone and a molecule of $\mathbf{1}$. However the interaction of the hosted solvent with the complex molecule is essentially different in $\mathbf{1 b}$ and 1c phases. In $\mathbf{1 b}$, one can observe a hydrogen bond network

Table 1 Selected bond lengths, contacts ( $\AA$ ) and angles ( $\left.{ }^{\circ}\right)$ for 1a-c

\begin{tabular}{llcl}
\hline & \multicolumn{1}{l}{ 1a } & \multicolumn{1}{l}{ 1b } & 1c \\
\hline Au-Au (intramolecular) & 3.313 & 5.388 & 5.956 \\
P-P (intramolecular) & 3.760 & 4.337 & 4.454 \\
N-N (intramolecular) & 4.053 & 3.561 & 3.413 \\
Cl-Cl (intramolecular) & 3.679 & 6.664 & 7.460 \\
Distance between $p$-tolyl centroids & 8.289 & 6.868 & 6.932 \\
Cl-H $^{\text {acetone }}$ shortest distance & - & 2.826 & 3.280 \\
$p^{-T o l y l}{ }^{\text {centroid_-Hacetone }}$ shortest distance & - & 3.169 & 3.365 \\
O $^{\text {acetone }} \mathrm{H}^{\mathrm{CH}_{2}}$ of PNNP & - & 2.476 & - \\
Torsion angle of pyridine rings & 80.21 & 36.26 & 0 \\
Au-P-P angles & 83.59 & 103.62 & 109.83
\end{tabular}


formed by the relatively short contacts of the methylene protons of the PNNP ligand and an oxygen atom of acetone $(2.426 \AA)$ together with bonding of a coordinated chloride ion and methyl protons of acetone (2.876 ̊) (see Fig. 1, top and Table 1). It was found that the methyl protons of acetone are located close to the $p$-tolyl fragment and the shortest distance between the centroid of a phenyl ring and these protons is $3.169 \AA$. These interactions give infinite chains of $\{1$-acetone $\}$ aggregates (see Fig. 1, bottom). In the crystal phase of (1c, one of the solvent molecules is disposed outside the "basket" whereas the other sits in the cavity but the distances between acetone and coordinated chlorides and between acetone and a phenyl ring are substantially longer (3.280 and 3.365 A, respectively) than those in $\mathbf{1 b}$ and no contacts between acetone oxygen and the PNNP protons were found. These crystallographic peculiarities proved to be a key reason for substantial variations in the photophysical properties of the crystalline phases of 1 (see Fig. 2). It is worth noting that the 1a and 1c phases are somewhat similar in the absence of a strong and highly organized hydrogen bond network found in $\mathbf{1 b}$ that in turn results in similarity of their photophysical characteristics and made them substantially different from those found for $\mathbf{1 b}$. The formation of different crystalline phases of 1 provides a unique opportunity to study the effect of molecular conformation, packing arrangement and "host-guest" interactions on the solid state luminescence properties.

\section{Photophysical properties of complex 1 in the solid phase}

It was found that complex 1 displays very weak emission in solution at room temperature but shows appreciable luminescence in solution at $77 \mathrm{~K}$ and in the solid state, in the latter case, the emission characteristics being determined by the variations in the structure of the crystalline phase. The luminescence spectra of free PNNP in the solid state and those of solid state samples of 1 are shown in Fig. 3, and the emission characteristics are given in Table 2 .

The room temperature solid state emission of free PNNP is a typical fluorescence with a Stokes shift of about $80 \mathrm{~nm}$ and lifetime in the nanosecond domain. In contrast to the ligand luminescence, the emission of 1a-c displays Stokes shifts of $c a .180 \mathrm{~nm}$ and excited state lifetimes in the microsecond domain, which are indicative of the triplet origin of the emission observed, i.e. phosphorescence.

The solid-state samples of 1a-c display an identical clearcut excitation band with two maxima at 335 and $375 \mathrm{~nm}$, which point to an essentially similar mechanism of excitation, which starts from the electron transfer between the orbitals of the same nature. The luminescence bands of $1 \mathrm{a}$ and

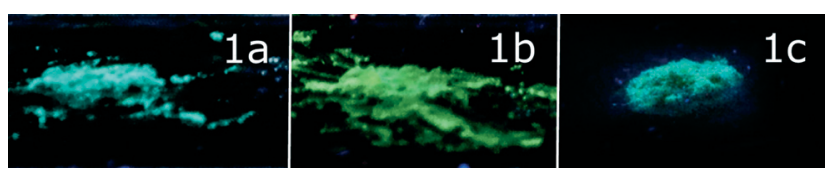

Fig. 2 1a-c phases under UV lamp irradiation $\left(\lambda_{\mathrm{exc}}=365 \mathrm{~nm}\right)$.

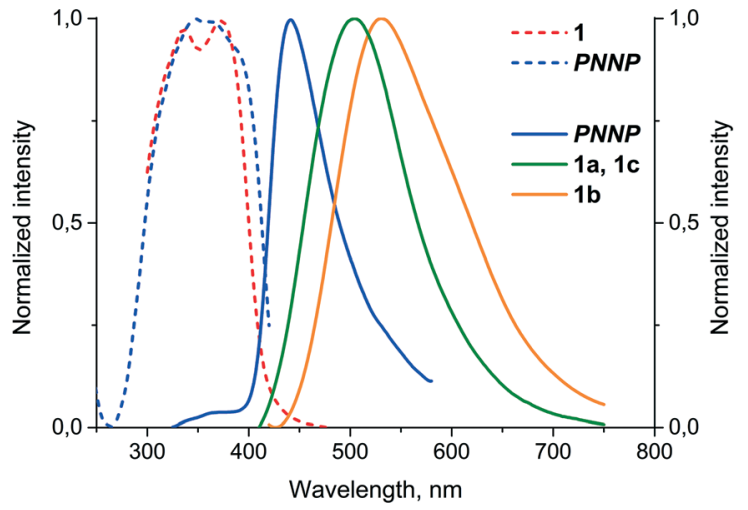

Fig. 3 Normalized excitation (dash lines) and emission (solid lines) spectra of free PNNP and the crystalline phases of $1\left(\lambda_{\text {exc }}=340 \mathrm{~nm}\right.$, room temperature).

1c also coincide to give green emission at $500 \mathrm{~nm}$; the emission maximum of $\mathbf{1 b}$ is red shifted by $35 \mathrm{~nm}$, changing the colour of emission into a greenish-yellow one. The identical emission bands of 1a and 1c, in spite of aurophilic interactions in $1 \mathrm{a}$ and its absence in 1c, clearly point to the mostly intraligand (IL) nature of the emissive excited state. The effect of a solvent on luminescence in the cases of $1 \mathrm{a}$ and $\mathrm{c}$ is negligible because there is nearly no interaction between solvent molecules and coordinated PNNP, which is evidently the chromophoric centre of the $\{$ complex-solvent $\}$ aggregate (see the DFT calculations section vide infra). Thus, even a relatively weak interaction of an acetone molecule (short $\mathrm{O}^{\text {acetone }}-\mathrm{H}\left(\mathrm{CH}_{2}\right.$ of PNNP) contacts) with coordinated PNNP in $\mathbf{1 b}$ results in substantial variation of the emission characteristics. This observation indicates a crucial influence of the local solvent interaction with the chromophoric centre on the photophysical parameters of complex $\mathbf{1}$ in the crystalline phases. The cooperative electronic effect of the host-guest interaction is evidently increased by additional hydrogen bonding between acetone protons and coordinated chloride in the conjugated infinite \{complex-solvent chain (see Fig. 1). It has to be also noted at this point that the PXRD patterns of $1 \mathrm{a}-\mathbf{c}$ (Fig. S3 and Tables S2-S4 $\dagger$ ) are essentially similar to those calculated from the single crystal data, which makes discussion of the photophysical characteristics in relation to structural parameters revealed by XRD studies

Table 2 Solid state emission characteristics of PNNP and 1a-c

\begin{tabular}{lllll}
\hline & $\lambda_{\text {exc }}{ }^{a}{ }^{n} \mathrm{~nm}$ & $\lambda_{\mathrm{em}}{ }^{b}{ }^{n} \mathrm{~nm}$ & $\tau, \mathrm{ns}$ & $\Phi, \%$ \\
\hline PNNP & 340 & 440 & $0.3(0.49) ; 81(0.42)$ & $<1$ \\
1a & 335,375 & 500 & $47(0.51) ; 441(0.49)$ & 1.2 \\
1b & 335,375 & 535 & $198(0.42) ; 925(0.58)$ & 1.5 \\
1c & 335,375 & 500 & $33(0.34) ; 191(0.66)$ & 1.2 \\
1 $^{c}$ & & 520 & & \\
$\mathbf{1}^{d}$ & & 490 & &
\end{tabular}

${ }^{a}$ Excitation spectra were monitored at the maximum of the corresponding emission bands (440 nm for free PNNP; $500 \mathrm{~nm}$ for 1, 1a, 1c; $535 \mathrm{~nm}$ for 1b). ${ }^{b} \lambda_{\text {exc }}=340 \mathrm{~nm}$ (room temperature) and $\lambda_{\mathrm{exc}}=$ $365 \mathrm{~nm}(77 \mathrm{~K}){ }^{c}$ DCM matrix at $77 \mathrm{~K} .{ }^{d}$ Acetone matrix at $77 \mathrm{~K}$. 
possible. The presence of some signals of another phase may be assigned to the loss of the solvent upon powder sample preparation.

\section{Photophysical properties of complex 1 in frozen solvents}

Upon freezing in liquid nitrogen, the solution of 1 starts to intensely exhibit luminescence and the emission colour being different in various solvents (see Fig. 4 and Table 2). The frozen dichloromethane solution of 1 displays a yellowgreenish emission, which is $20 \mathrm{~nm}$ red-shifted relative to the emission of $1 \mathrm{a}$ and $\mathbf{c}$ while in frozen acetone the band maximum is $45 \mathrm{~nm}$ blue-shifted relative to the room temperature emission of $\mathbf{1 b}$. The complex in neat acetone solution evidently tends to form an aggregate with the solvent molecule, in particular at low temperature. Thus, the observed blue shift in the emission of the frozen solution compared to the room temperature band of $\mathbf{1 b}$ is a typical phenomenon due to stabilization of the ground state at $77 \mathrm{~K}$. The red shift in the emission band of $\mathbf{1}$ in frozen dichloromethane compared to that of $1 \mathrm{a}$ at room temperature may be assigned to more effective relaxation of the triplet excited state for an unconstrained molecule in the solvent matrix compared to an analogous process in the solid phase where strong intermolecular interactions in the crystal cell do not allow deep intramolecular rearrangement. The emission switch-on/ switch-off upon temperature variations is reversible and warming the frozen solution results in luminescence quenching, while refreezing recovers the emission.

It is worth noting that the concentration of $\mathbf{1}$ in solution does not affect the emission characteristics both at room and low temperatures, which is indicative of the absence of complex aggregation and/or formation of an exciplex in solution.

\section{DFT calculations}

The absorption spectrum of $\mathbf{1}$ in solution resembles that of a free PNNP ligand, for which TDDFT calculations show two bands with maxima around $355 \mathrm{~nm}$ and $250 \mathrm{~nm}$. For PNNP, three transitions (364 nm, $359 \mathrm{~nm}$, and $352 \mathrm{~nm}$ ) corresponding to electron transfer from $p$-tolyl fragments to pyridyl rings dominate in the lower-energy band. For 1, the positions of the low-energy and high-energy bands remain unchanged,
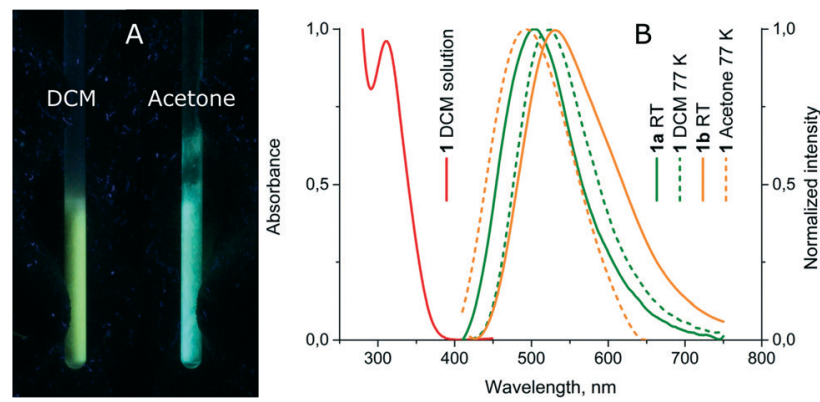

Fig. 4 (A) Photos of luminescence of 1 in frozen DCM and acetone solutions under UV lamp irradiation; (B) normalized absorption and emission spectra of 1. suggesting that the photophysical behaviour of the complex is largely determined by the properties of the ligand. The energy of the lowest triplet state of 1 obtained from TDDFT calculations was $391 \mathrm{~nm}$ compared to $382 \mathrm{~nm}$ for free PNNP. The nature of this state is predominantly defined by the two highest occupied orbitals and two lowest virtual orbitals of 1 . For the isolated complex 1, which can be considered as a simplified model of $\mathbf{1 a}$, the two highest occupied orbitals (HOMO and HOMO-1) are mostly localized at the $p$-tolyl fragments of the ligand. However, noticeable contributions from gold and phosphorous atoms can also be found. Both LUMO and LUMO+1 have large contributions from the pyridyl fragments, though LUMO also involves orbitals of both gold atoms, which form an intramolecular aurophilic bond (see Fig. S5†).

Addition of one or two acetone molecules located at the same position, as found in $\mathbf{1 b}$ and $\mathbf{1 c}$ crystalline phases, appears to have no immediate effect on the computed spectral properties of 1 . However, the insertion of an acetone molecule between $p$-tolyl fragments leads to the loss of aurophilic contact. As a result, the contribution of gold atoms into the highest occupied orbitals is noticeably lower than for an isolated complex, while the lowest vacant orbitals no longer indicate the presence of $\mathrm{Au}-\mathrm{Au}$ bonding (see Fig. S6 and $\mathrm{S} 7 \dagger$ ).

For the acetone molecule located between the $p$-tolyl fragments in $\mathbf{1 b}$ and 1c, the smallest distance between methyl hydrogens and a chloride ion is at least $3 \AA$ A. Therefore, this solvent molecule is unlikely to be capable of having strong interactions with the complex. This conclusion is supported by the amount of charge transfer from the acetone molecule to the complex, which does not exceed $0.05 e$ (as estimated from Mulliken atomic charges). In contrast to that, the acetone molecule located on the other side of the PNNP ring between the pyridyl fragments has a more favourable orientation, forming $\mathrm{O}-\mathrm{H}$ contacts with interatomic distances of 2.2-2.5 A. As a result, the charge transfer to the complex for this molecule is close to $0.1 e$, which is comparable to the effect of some coordinating solvents. For the aggregate with two acetone molecules, which was used to model the $\mathbf{1 b}$ phase, the total charge transfer from solvent molecules is 0.14e., i.e., three times larger than for the system modelling the 1c phase. Stronger interactions with acetone molecules together with the effect induced by cooperative interactions in the infinite chain $\{\text { complex-solvent }\}_{n}$ may be responsible for the observed difference in emission of the $\mathbf{1 b}$ and $\mathbf{1 c}$ phases.

Thus, the results of model DFT calculations, which take into account local interactions of an isolated complex molecule with the solvents found in the solid state, support the ligand-based mechanism of emission and point to the potentially important role of solvent molecules co-crystallized with the complex in the $\mathbf{1 b}$ and $\mathbf{1 c}$ phases. However, the study of a molecule of complex 1 in solution (with or without additional solvent molecules) is unable to provide an accurate description of the solid-state photophysical behaviour for two primary reasons. First of all, constrained geometry 
optimizations carried out for a single molecule of 1 cannot provide a correct description of excited state relaxation in the solid state. Secondly, the modelling of media effects under the framework of the PCM approach is unlikely to give an adequate account of the influence of the crystalline environment on the electronic structure of 1 . Therefore, dedicated solid-state quantum chemical calculations are necessary to obtain a fully quantitative description of the emissive properties of the complex.

\section{Conclusions}

In conclusion, we demonstrated that a binuclear Au(I) complex based on a flexible aminomethylphosphine template could exhibit stimuli-responsive luminescence properties. Different crystalline phases of the $\mathrm{Au}(\mathrm{I})$ complex were obtained using slight modification of the crystallization conditions. Careful XRD analysis showed that molecular conformations, packing arrangements and non-covalent interactions between the binuclear $\mathrm{Au}(\mathrm{I})$ complex and a solvent (acetone) molecule are interdependent factors and their combination determines the solid-state luminescence properties. The observed reversible interconversion between the different crystalline phases of the Au(I) complex occurs as a vapourstimulated \{single crystal-to-single crystal\} transformation between crystalline phases and we believe that these results may provide ideas for the design of novel stimuli-responsive luminescent materials.

\section{Acknowledgements}

The authors (I. D. S., E. I. M., A. A. K.) greatly appreciate the financial support of the Russian Science Foundation, grant 15-13-30031. This work was carried out using equipment of core facilities of St. Petersburg State University Research Park: Centre for Magnetic Resonance, Centre for Optical and Laser Materials Research, Centre for Chemical Analysis and Materials Research, the X-ray Diffraction Centre, and the Thermogravimetric and Calorimetric Research Centre.

\section{Notes and references}

1 G.-J. Zhou and W.-Y. Wong, Chem. Soc. Rev., 2011, 40, 2541; J. Carlos Lima and L. Rodriguez, Chem. Soc. Rev., 2011, 40, 5442; X. Zhang, B. Li, Z.-H. Chen and Z.-N. Chen, J. Mater. Chem., 2012, 22, 11427; O. S. Wenger, Chem. Rev., 2013, 113, 3686; Z. Hu, B. J. Deibert and J. Li, Chem. Soc. Rev., 2014, 43, 5815.

2 R. C. Ropp, Luminescence and the Solid State, Elsevier Science, 2004; H. Schmidbaur and A. Schier, Chem. Soc. Rev., 2012, 41, 370; T. Lasanta, J. M. Lopez-de-Luzuriaga, M. Monge, M. E. Olmos and D. Pascual, Chem. - Eur. J., 2013, 19, 4754.

3 I. O. Koshevoy, Y.-C. Chang, A. J. Karttunen, M. Haukka, T. Pakkanen and P.-T. Chou, J. Am. Chem. Soc., 2012, 134, 6564.

4 J. R. Shakirova, E. V. Grachova, A. S. Melnikov, V. V. Gurzhiy, S. P. Tunik, M. Haukka, T. A. Pakkanen and I. O. Koshevoy, Organometallics, 2013, 32, 4061.
5 A. J. Lees, Chem. Rev., 1987, 87, 711; E. J. Fernandez, M. C. Gimeno, A. Laguna, J. M. Lopez-de-Luzuriaga, M. Monge, P. Pyykko and D. Sundholm, J. Am. Chem. Soc., 2000, 122, 7287; R. L. White-Morris, M. M. Olmstead, F. Jiang, D. S. Tinti and A. L. Balch, J. Am. Chem. Soc., 2002, 124, 2327; V. W.-W. Yam, C.-L. Chan, C.-K. Li and K. M.-C. Wong, Coord. Chem. Rev., 2001, 216-217, 173; Y.-A. Lee, J. E. McGarrah, R. J. Lachicotte and R. Eisenberg, J. Am. Chem. Soc., 2002, 124, 10662; M. A. Omary, M. A. Rawashdeh-Omary, M. W. A. Gonser, O. Elbjeirami, T. Grimes, T. R. Cundari, H. V. K. Diyabalanage, C. S. P. Gamage and H. V. R. Dias, Inorg. Chem., 2005, 44, 8200; E. M. Gussenhoven, J. C. Fettinger, D. M. Pham, M. M. Malwitz and A. L. Balch, J. Am. Chem. Soc., 2005, 127, 10838; E. J. Fernandez, A. Laguna, J. M. Lopez-de-Luzuriaga, M. Monge, M. Montiel, M. E. Olmos and M. Rodriguez-Castillo, Organometallics, 2006, 25, 3639; J. M. Lopez-de-Luzuriaga, M. Monge, M. E. Olmos, D. Pascual and M. Rodriguez-Castillo, Inorg. Chem., 2011, 50, 6910; Q. Zhao, C. Huang and F. Li, Chem. Soc. Rev., 2011, 40, 2508; I. O. Koshevoy, C.-L. Lin, A. J. Karttunen, M. Haukka, C.-W. Shih, P.-T. Chou, S. P. Tunik and T. A. Pakkanen, Chem. Commun., 2011, 47, 5533; J. Liang, Z. Chen, J. Yin, G.-A. Yu and S. H. Liu, Chem. Commun., 2013, 49, 3567.

6 M. A. Mansour, W. B. Connick, R. J. Lachicotte, H. J. Gysling and R. Eisenberg, J. Am. Chem. Soc., 1998, 120, 1329; J. Lefebvre, R. J. Batchelor and D. B. Leznoff, J. Am. Chem. Soc., 2004, 126, 16117; D. B. Leznoff and J. Lefebvre, Gold Bull., 2005, 38, 47; E. J. Fernandez, J. M. Lopez-de-Luzuriaga, M. Monge, M. E. Olmos, R. C. Puelles, A. Laguna, A. A. Mohamed and J. P. Fackler Jr., Inorg. Chem., 2008, 47, 8069; C. E. Strasser and V. J. Catalano, J. Am. Chem. Soc., 2010, 132, 10009; C. Jobbagy, T. Tunyogi, G. Palinkas and A. Deak, Inorg. Chem., 2011, 50, 7301.

7 X. He and V. W.-W. Yam, Coord. Chem. Rev., 2011, 255, 2111; Y.-P. Zhou, E.-B. Liu, J. Wang and H.-Y. Chao, Inorg. Chem., 2013, 52, 8629.

8 Z. Assefa, M. A. Omary, B. G. McBurnett, A. A. Mohamed, H. H. Patterson, R. J. Staples and J. P. Fackler, Inorg. Chem., 2002, 41, 6274; E. J. Fernandez, J. M. Lopez-de-Luzuriaga, M. Monge, M. E. Olmos, J. Perez, A. Laguna, A. A. Mohamed and J. P. Fackler Jr., J. Am. Chem. Soc., 2003, 125, 2022; V. J. Catalano and S. J. Horner, Inorg. Chem., 2003, 42, 8430; E. J. Fernandez, A. Laguna and J. M. Lopez-de-Luzuriaga, Coord. Chem. Rev., 2005, 249, 1423; J. Schneider, Y.-A. Lee, J. Perez, W. W. Brennessel, C. Flaschenriem and R. Eisenberg, Inorg. Chem., 2008, 47, 957; A. Deak, T. Tunyogi and G. Palinkas, J. Am. Chem. Soc., 2009, 131, 2815; A. M. Kuchison, M. O. Wolf and B. O. Patrick, Chem. Commun., 2009, 7387; Z. Chi, X. Zhang, B. Xu, X. Zhou, C. Ma, Y. Zhang, S. Liu and J. Xu, Chem. Soc. Rev., 2012, 41, 3878; X. Zhang, Z. Chi, Y. Zhang, S. Liu and J. Xu, J. Mater. Chem. C, 2013, 1, 3376; K. Kawaguchi, T. Seki, T. Karatsu, A. Kitamura, H. Ito and S. Yagai, Chem. Commun., 2013, 49, 11391; J. Liang, Z. Chen, L. Xu, J. Wang, J. Yin, G.-A. Yu, Z.-N. Chen and S. H. Liu, J. Mater. Chem. C, 2014, 2, 2243; A. A. Penney, V. V. Sizov, E. V. Grachova, D. V. Krupenya, V. V. Gurzhiy, G. L. Starova and S. P. Tunik, Inorg. Chem., 2016, 55, 4720. 
9 C. Jobbagy and A. Deak, Eur. J. Inorg. Chem., 2014, 4434; E. C.-C. Cheng, W.-Y. Lo, T. K.-M. Lee, N. Zhu and V. W.-W. Yam, Inorg. Chem., 2014, 53, 3854; K. Fujisawa, Y. Okuda, Y. Izumi, A. Nagamatsu, Y. Rokusha, Y. Sadaike and O. Tsutsumi, J. Mater. Chem. C, 2014, 2, 3549; N. Nasser and R. J. Puddephatt, Inorg. Chim. Acta, 2014, 409, 238; E. R. T. Tiekink, Coord. Chem. Rev., 2014, 275, 130.

10 A. A. Karasik, A. S. Balueva, E. I. Musina and O. G. Sinyashin, Mendeleev Commun., 2013, 23, 237; E. I. Musina, A. A. Karasik, O. G. Sinyashin and G. N. Nikonov, Adv. Heterocycl. Chem., 2015, 117, 83.

11 A. A. Karasik, R. N. Naumov, O. G. Sinyashin, G. P. Belov, H. V. Novikova, P. Lonnecke and E. Hey-Hawkins, Dalton Trans., 2003, 2209.
12 A. A. Karasik, R. N. Naumov, R. Sommer, O. G. Sinyashin and E. Hey-Hawkins, Polyhedron, 2002, 21, 2251.

13 E. I. Musina, V. V. Khrizanforova, I. D. Strelnik, M. I. Valitov, Y. S. Spiridonova, D. B. Krivolapov, I. A. Litvinov, M. K. Kadirov, P. Lonnecke, E. Hey-Hawkins, Y. H. Budnikova, A. A. Karasik and O. G. Sinyashin, Chem. - Eur. J., 2014, 20, 3169.

14 S. K. Latypov, A. G. Strelnik, S. N. Ignatieva, E. Hey-Hawkins, A. S. Balueva, A. A. Karasik and O. G. Sinyashin, J. Phys. Chem. A, 2012, 116, 3182.

15 G. M. Sheldrick, Acta Crystallogr., Sect. A: Found. Crystallogr., 2008, 64, 112; O. V. Dolomanov, L. J. Bourhis, R. J. Gildea, J. A. K. Howard and H. Puschmann, J. Appl. Crystallogr., 2009, 42, 339; CrysAlisPro, Agilent Technologies, Version 1.171.36.20 (release 27-06-2012); A. L. Spek, PLATON, Utrecht University, Utrecht, The Netherlands, 2005. 